\title{
China county based COPD screening and cost-effectiveness analysis
}

\author{
Minghua Du ${ }^{1}$, Hao Hu${ }^{2}$, Lei Zhang ${ }^{1}$, Wenpeng Liu ${ }^{1}$, Tianbao Chu ${ }^{1}$, Guoxia $\mathrm{Wu}^{1}$, Xiaoling Wang ${ }^{1}$, \\ Ling Li ${ }^{1}$, Jing Wang ${ }^{1}$, Lingling Zheng ${ }^{1}$, Shuchen Bai ${ }^{1}$
}

${ }^{1}$ Department of Pulmonary and Critical Care Medicine, Fengning Manchu Autonomous County Hospital of Chengde medical college, Chengde, China; ${ }^{2}$ Institute of Chinese Medical Sciences, University of Macau, Macau Special Administrative Region, China

Contributions: (I) Conception and design: S Bai, M Du; (II) Administrative support: S Bai, M Du; (III) Provision of study materials or patients: $\mathrm{M}$ Du, L Zhang, W Liu, T Chu, G Wu, X Wang, L Li, J Wang, L Zheng; (IV) Collection and assembly of data: M Du, L Zhang, W Liu, T Chu, G Wu, X Wang, L Li, J Wang, L Zheng; (V) Data analysis and interpretation: H Hu; (VI) Manuscript writing: All authors; (VII) Final approval of manuscript: All authors.

Correspondence to: Shuchen Bai. Pulmonary and Critical Care Medicine, Fengning Manchu Autonomous County Hospital of Chengde Medical College, Chengde, China. Email: fnbaishuchen@163.com.

Background: Early diagnosis and treatment of chronic obstructive pulmonary disease (COPD) can improve pulmonary function and reduce the incidence of exacerbations of acute COPD, thereby improving the patient's quality of life. In China, due to limited medical resources, COPD patients often cannot be diagnosed and treated early, so the benefits of early screening of patients with COPD high risk still lack effective supporting data.

Methods: Based on the data collected through the "Dual-lung screening initiative" performed by the Datan Health Center in Fengning Manchu Autonomous County on July 12 and July 19, 2020, the patients with COPD high risk who underwent early COPD screening were evaluated. The screened patients were mainly smokers aged over 45 and those with long-term exposure to secondhand smoke, underlying lung diseases, a family history of lung diseases, or respiratory symptoms. After filling out the COPD-population screener (COPD-PS) questionnaire, those who had a score of above 5 were subjected to the portable pulmonary function test. Subjects with a forced expiratory volume in 1 s/forced vital capacity $\left(\mathrm{FEV}_{1} /\right.$ FVC) ratio $<0.7$ were diagnosed with COPD. A cost-effectiveness analysis model was applied to assess the screening's economic efficiency. The model was constructed through a combination of a decision tree and a Markov model, which enabled the simulation of the disease progression of COPD high risk patients under the condition of being screened or not being screened, to evaluate the incremental cost-effectiveness ratio between the two conditions.

Results: A total of 700 questionnaires were issued for screening and 379 questionnaires were valid, and 92 patients were diagnosed with COPD $(24.27 \%)$. The modeling results showed that among patients with COPD high risk, those receiving early screening had an increase in quality-adjusted life years (QALYs) by 0.28 units over those who did not, and a cost of 6,366.19 Renminbi (RMB) would be needed, which was much lower than the set willingness-to-pay threshold (70,888.99 RMB) [an equivalent of the 2019 per capita gross domestic product (GDP)].

Conclusions: For COPD high risk patients, receiving early screening has a cost-effective advantage over no screening. Therefore, early screening should be vigorously promoted to COPD high risk patients.

Koywords: Chronic obstructive pulmonary disease (COPD); questionnaire screening; cost-effectiveness analysis; China county

Submitted Feb 22, 2021. Accepted for publication Apr 21, 2021.

doi: $10.21037 /$ apm-21-812

View this article at: http://dx.doi.org/10.21037/apm-21-812 


\section{Introduction}

Chronic obstructive pulmonary disease (COPD) is a preventable and treatable disease characterized by continuous airflow limitation and incomplete reversibility that leads to a series of complications. Besides, COPD has been recognized as an independent risk factor for lung cancer $(1,2)$. Early diagnosis of COPD, i.e., the diagnosis in the early stage of COPD when the patient does not manifest any symptoms and the lung radiographic examination does not show obvious emphysema changes, can slow the pulmonary function decline, reduce the incidence of acute exacerbation of COPD, and thereby improve the patient's quality of life, which are of great significance for COPD treatment (3). In China, due to limited medical resources, early diagnosis and treatment are often not accessible to COPD patients, which has caused the very low awareness rate and low early diagnosis rate of COPD patients in China, especially in rural counties or other rural areas (4). According to the China pulmonary health $(\mathrm{CPH})$ study, among the nearly 100 million COPD patients in China, more than $50 \%$ live in rural counties. The diagnosis rate and pulmonary function test rate of COPD patients in these areas are lower than those of the patients in cities (5). The low COPD awareness rate of residents of rural counties and the uneven development between rural counties have made the control of respiratory diseases particularly challenging in these rural areas.

Pulmonary function testing is the gold standard for the diagnosis of COPD. In primary medical institutions and rural areas, it is difficult to conduct extensive testing and early screening on the population due to the lack of equipment and technical personnel. Thus, to find a simple, efficient and accurate screening method to replace pulmonary function testing to make a more accurate screening of COPD in primary medical institutions and rural areas has become the focus of attention of medical workers. Portable pulmonary function tester and COPD screening questionnaire were two major methods for COPD screening in rural areas at present (6-8). However, there are still some shortcomings such as uncertain screening standards, unstable screening population and weak pertinence. Therefore, we attempted to first screen for the high-risk factors for COPD in a primary screening, which was followed by targeted pulmonary function testing using a pulmonary function instrument. This strategy aimed not only to improve the detection rate of COPD but also to reduce the cost of examinations and would thus be beneficial to the early diagnosis and management of COPD. We evaluated the economics of early screening for COPD high risk patients by analyzing the data collected by the Datan Health Center of Fengning Manchu Autonomous County during the "Dual-lung (COPD and lung cancer) screening initiative". Moreover, based on the data collected during the "Dual-lung screening initiative", we also analyzed the cost-effectiveness of the screening on the COPD high risk population using a health-economic model to provide data support for optimizing the screening strategy. We present the following article in accordance with the MDAR reporting checklist (available at http://dx.doi.org/10.21037/ apm-21-812).

\section{Methods}

\section{Research subjects}

In July 2020, the Fengning Manchu Autonomous County Health Bureau implemented the "Dual-lung screening initiative" within the county, which was jointly undertaken by the Fengning County Hospital, primary township hospitals, and AstraZeneca. The county hospital was responsible for organizing screening experts and professionals, who brought necessary detection and testing equipment on site and provided free consultations and health education services. They set up an expert group to conduct consultations on screened patients and determine the diagnosis and treatment process as well as the subsequent treatment measures. The subjects of this study were from the participants in the "Dual-lung screening initiative" activities conducted in the Datan Health Center of Fengning Manchu Autonomous County on July 7 and July 12, 2020. They were mostly smokers aged over 45 and people with long-term exposure to secondhand smoke, underlying lung diseases, family history of lung disease, or respiratory symptoms such as suffocation, wheezing, and coughing. Exclusion criteria: (I) myocardial infarction, stroke, or shock in the past 3 months; (II) severe heart failure, severe arrhythmias, or unstable angina in the past 4 weeks; (III) massive hemoptysis in the past 4 weeks; (IV) seizures that needed medical treatment; (V) unmanaged hypertension (systolic blood pressure $>200 \mathrm{mmHg}$, diastolic blood pressure $>100 \mathrm{mmHg}$ ); (VI) aortic aneurysm; (VII) severe hyperthyroidism; (VIII) recent eye, ear, or brain surgery; (IX) resting heart rate $>120$ beats/min; (X) pneumothorax or giant bullae but no surgery plan; (XI) pregnancy; (XII) tympanic membrane perforation; 
(XIII) stress urinary incontinence; (XIV) dementia, mental disability, or consciousness disturbance; (XV) respiratory tract infection in the past 4 weeks; (XVI) low immunity and susceptibility to infection; and (XVII) respiratory infectious diseases (tuberculosis, influenza). This study was approved by the ethics committee of Fengning Manchu Autonomous County Hospital (approval number: 2021-01), and all subjects signed the informed consent agreement. All procedures performed in this study involving human participants were in accordance with the Declaration of Helsinki (as revised in 2013).

\section{Screening method}

In the screening, first the participants aged over 45 from Datan Township were asked to fill out a questionnaire that asked for the participant's personal and contact information plus smoking and drinking history, as well as the chronic obstructive pulmonary disease population screener (COPD-PS) questionnaire (9). Then, the respondents who completed the screening questionnaires were subjected to lung auscultation and detailed consultation. On the highrisk population (with a COPD-PS score $\geq 5$ ), pulmonary ventilation function tests were performed on site with the Jaeger Pulmonary Function Tester (MasterScreen, CareFusion Germany 234 GmbH, Hoechberg, Germany). Those who had a forced expiratory volume in one second/ forced vital capacity $\left(\mathrm{FEV}_{1} / \mathrm{FVC}\right)$ ratio $<0.7$ were diagnosed with COPD (10), for which the County Hospital provided a green passage for further diagnosis and treatment with standardized medication and patient management and follow-up while recording their diagnosis and treatment information.

The content of the COPD screening questionnaire included (I) basic patient information, e.g., age, sex, living environment, smoking and drinking history, occupational exposure, family history, medical history, etc.; (II) investigations related to respiratory symptoms, e.g., experiencing frequent short of breath in the past month, sputum, reduced activity due to breathing problems, smoking history, and oil fume exposure history.

\section{Model design}

The clinical efficacy and economics of the screening program were analyzed using the data collected during the screening and the health-economic model that we devised (11), which has already been accepted for publication in NPF
Primary Care Respiratory Medicine. The cost-effectiveness analysis model contains two parts, i.e., the decision tree model and the Markov model. The decision tree model simulates the screening process, while the Markov model simulates the disease progression of COPD high risk patients, in which the path of disease progression is characterized by different severity levels (categorized based on the percentage of forced expiratory volume in one second $\left(\mathrm{FEV}_{1}\right)$ out of the predicted value). The model simulated 15 years in monthly cycles. The relevant parameters of patients with COPD who did not undergo the screening were obtained from expert interviews. The utility values of different severity levels adopted in the model were derived from the published literature. The costs considered in the model included the cost of screening, the cost of diagnosis and examination, and the cost of medication. The information about the first two costs was obtained through expert interviews, while the cost of medication was calculated from the unit prices of the medicines used, which were derived from the Chinese Hospital Drug Use Followup Database of IQVIA. Both clinical efficacy parameters and cost parameters in the model were discounted by $3.5 \%$. The incremental cost-effectiveness ratio, which refers to the ratio of the increment of costs over the quality-adjusted life year (QALY) increment under the two conditions (undergoing screening and not undergoing screening), was used as the main evaluation index. QALY refers to the product of the number of the patient's survival years and the utility value of the intervention. In addition, we performed One-way Deterministic sensitivity (DSA) and probabilistic sensitivity analysis (PSA) to evaluate the stability of the modeling results.

\section{Statistical analysis}

Quantitative data are presented as descriptive statistics: number of cases, mean, standard deviation, minimum, maximum, median, and the first and the third quantiles. Qualitative data are reported as the frequency and composition ratio. The statistical analyses were done with R4.0.3 software, and the economic modeling was performed in Microsoft Excel.

\section{Results}

\section{Screening results}

A total of 700 questionnaires were distributed in two 
Table 1 Statistics of the screening

\begin{tabular}{lc}
\hline Indicator (N, \%) & $\begin{array}{c}\text { Number of cases } \\
\text { (proportion) }\end{array}$ \\
\hline Number of questionnaires distributed & 700 \\
Number of questionnaires received & 544 \\
Number of valid questionnaires & 379 \\
High-risk group & $202(53.30 \%)$ \\
Low-risk group & $177(46.70 \%)$ \\
Final diagnosis of COPD group & $92(24.27 \%)$ \\
Severe COPD & $19(9.41 \%)$ \\
Moderate COPD & $22(10.89 \%)$ \\
Mild COPD & $51(25.25 \%)$ \\
\hline
\end{tabular}

screening sessions, of which 544 were recovered, 379 of which were valid (Table 1). Based on the questionnaire score, 177 respondents were categorized as the low-risk group and 202 respondents as the high-risk group. The latter were subjected to pulmonary function testing, and ultimately, 92 respondents were diagnosed with COPD, accounting for $24.27 \%$ of the total. Of these, 51, 22, and 19 patients were diagnosed with mild, moderate, and severe COPD, respectively, accounting for $25.25 \%, 10.89 \%$, and $9.41 \%$ of the patients who underwent pulmonary function tests and $55.43 \%, 23.91 \%$, and $20.65 \%$ of the confirmed COPD patients.

\section{Characteristics of screening population}

The demographic and clinical characteristics of the study population, consisting of the 379 respondents of valid questionnaires, are shown in Table 2. The average age of the patients was 61.07 years (range 56 to 66 years), and men outnumbered women (64.38\% vs. $35.62 \%)$. Among them, 220 were smokers, with an average smoking history of 31.66 years (range 20 to 40 years). The vast majority had no history of mine dust exposure. Many patients had hypertension, emphysema, or heart disease. The average age of the 92 confirmed COPD patients was 62.2 years old. Eighteen of them were female, accounting for $19.57 \%$.

\section{Cost-effectiveness analysis}

We adopted an existing economic model to analyze the data. The simulation results using the model and the
Table 2 Demographic and clinical characteristics of the patients

\begin{tabular}{|c|c|c|}
\hline Factor & Statistic & Value \\
\hline \multirow[t]{4}{*}{ Age (years) } & $\mathrm{N}$ & 379 \\
\hline & $\begin{array}{c}\text { Mean } \pm \text { standard } \\
\text { deviation }\end{array}$ & $61.07 \pm 8.17$ \\
\hline & $\begin{array}{l}\text { Median [minimum- } \\
\text { maximum] }\end{array}$ & $61[30-90]$ \\
\hline & $\begin{array}{c}\text { First quantile-third } \\
\text { quantile }\end{array}$ & $56-66$ \\
\hline \multirow[t]{2}{*}{ Sex } & Male & $244(64.38 \%)$ \\
\hline & Female & $135(35.62 \%)$ \\
\hline \multirow[t]{3}{*}{ Smoker } & Yes & 220 (58.05\%) \\
\hline & No & 144 (37.99\%) \\
\hline & No information & 15 (3.96\%) \\
\hline \multirow[t]{3}{*}{$\begin{array}{l}\text { Smoking history } \\
\text { (years) }\end{array}$} & $\begin{array}{c}\text { Mean } \pm \text { standard } \\
\text { deviation }\end{array}$ & $31.66 \pm 12.62$ \\
\hline & $\begin{array}{l}\text { Median [minimum- } \\
\text { maximum] }\end{array}$ & $30[0.5-60]$ \\
\hline & $\begin{array}{l}\text { First quantile-third } \\
\text { quantile }\end{array}$ & $20-40$ \\
\hline \multirow{3}{*}{$\begin{array}{l}\text { From a poor } \\
\text { household }\end{array}$} & Yes & $90(23.75 \%)$ \\
\hline & No & $94(24.80 \%)$ \\
\hline & No information & 195 (51.45\%) \\
\hline \multirow{2}{*}{$\begin{array}{l}\text { Exposure history } \\
\text { (mining and dust } \\
\text { related work) }\end{array}$} & Yes & $45(11.87 \%)$ \\
\hline & No & $334(88.13 \%)$ \\
\hline \multirow{6}{*}{$\begin{array}{l}\text { Past medical } \\
\text { history }\end{array}$} & Hypertension & $33(8.71 \%)$ \\
\hline & Emphysema & $30(7.92 \%)$ \\
\hline & $\begin{array}{l}\text { Cardiovascular } \\
\text { disease }\end{array}$ & $23(6.07 \%)$ \\
\hline & Pneumonia & $14(3.69 \%)$ \\
\hline & $\begin{array}{l}\text { Pulmonary } \\
\text { Tuberculosis }\end{array}$ & $12(3.17 \%)$ \\
\hline & Cerebral infarction & $12(3.17 \%)$ \\
\hline \multirow[t]{3}{*}{$\begin{array}{l}\text { COPD-PS } \\
\text { questionnaire score }\end{array}$} & $\begin{array}{c}\text { Mean } \pm \text { standard } \\
\text { deviation }\end{array}$ & $6.59 \pm 1.81$ \\
\hline & $\begin{array}{l}\text { Median [minimum- } \\
\text { maximum] }\end{array}$ & $6[2-10]$ \\
\hline & $\begin{array}{l}\text { First quantile-third } \\
\text { quantile }\end{array}$ & $5-8$ \\
\hline
\end{tabular}


Table 3 Health-economic assessment results

\begin{tabular}{lcc}
\hline Variable & No screening (A) & Receiving questionnaire screening only (B) \\
\hline Cost $(¥)$ & 10,575 & 12,335 \\
Clinical effect & & 2.117 \\
$\quad$ Life year & 1.718 & 1.420 \\
Quality-adjusted life year & 1.143 & B vs. A \\
Incremental analysis & - & $¥ 1,760.38$ \\
Cost increment & - & 0.28 \\
Increment of quality adjusted life year & - & $6,366.19$ \\
Incremental cost-effectiveness ratio & & \\
\hline
\end{tabular}

epidemiological data of the patients collected in the screening sessions are shown in Table 3. Among the patients with COPD high risk, those receiving early screening had 0.28 more QALYs than those receiving no early screening, and for each unit increment in QALY, the treatment cost increased by 6,366.19 Renminbi (RMB). When setting the willingness-to-pay threshold (WTP) to the equivalent of the 2019 per capita gross domestic product (GDP) $(70,888.99$ RMB) (12), the extra treatment cost was much lower than the WTP, indicating that compared with patients receiving no questionnaire screening, those receiving questionnaire screening had a cost-effectiveness advantage.

\section{Sensitivity analysis}

We performed the One-way Deterministic Sensitivity Analysis and Probabilistic Sensitivity Analysis to examine the effect of changes to different parameters on the modeling result. The results of the One-way Deterministic Sensitivity Analysis are shown in Figure 1. The efficacy and cost discount rate were the factors with the highest impact. The results of the Probabilistic Sensitivity Analysis are shown in Figure 2. When varying the model parameters within the specified ranges, the probability that those undergoing the questionnaire screening had a cost-effective advantage over no screening was $100 \%$.

\section{Discussion}

According to the 2015 global disease burden data of COPD, 174.5 million people suffered from COPD, of whom 3.2 million died, accounting for $2.6 \%$ of the global disease burden (13). Recently, a large-scale population study on COPD was completed in China, and the results showed that the prevalence of COPD of rural residents (9.6\%) was higher than that urban residents $(7.4 \%)$, and the total number of COPD patients nationwide has reached 99.9 million, causing a great disease burden on society (5). COPD is a preventable and treatable disease characterized by airflow limitation and incomplete reversibility, with an insidious onset and only mild initial symptoms or no clinical symptoms at all, which can often cause the patients to miss the best timing of diagnosis and treatment (14). There are still many problems in the diagnosis and treatment of COPD, and the patients in primary medical institutions lack standardized diagnosis, treatment, and management, and they have low overall level of diagnosis and treatment.

In recent years, the Chinese government has gradually introduced a series of related policies to strengthen the management of COPD (15). The promulgation of these policies means that COPD in China, especially in primary medical institutions, will enter a new stage of more standardized, comprehensive, and in-depth management. Early detection, early diagnosis, and early treatment are effective measures to delay the progression of COPD and reduce the burden of disease. Missed early diagnosis of COPD is quite common, and the delay in the diagnosis is correlated with the severity of the disease. The early detection and early intervention for COPD can decelerate the decline of pulmonary function in patients with COPD (16), which is of great significance for the management of the disease. It is crucial to improve the early detection of COPD, especially by COPD screening of asymptomatic patients and high-risk populations (17).

County hospitals and township health centers are the cornerstones and cores of Chinese medical system, 


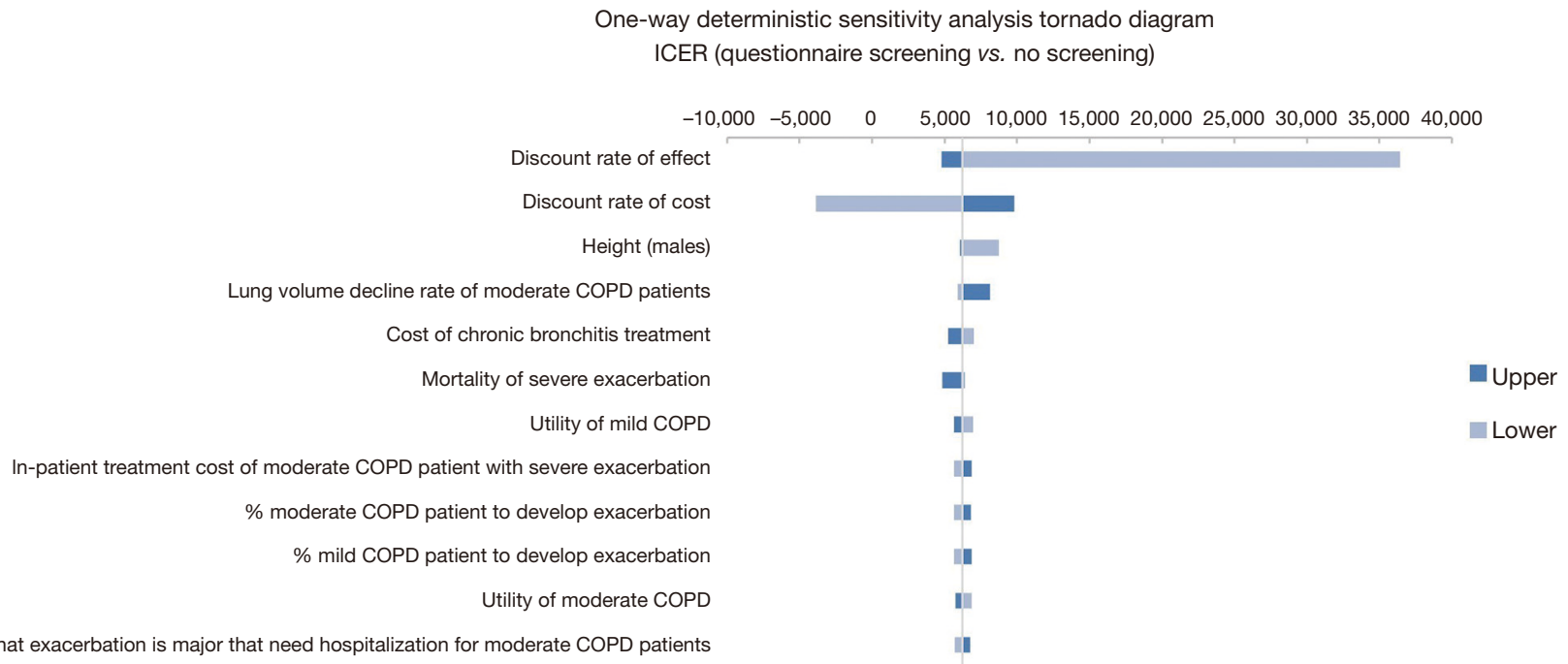

Probability that exacerbation is major that need hospitalization for moderate COPD patients

Figure 1 One-way deterministic sensitivity analysis result. ICER, incremental cost-effectiveness ratio.

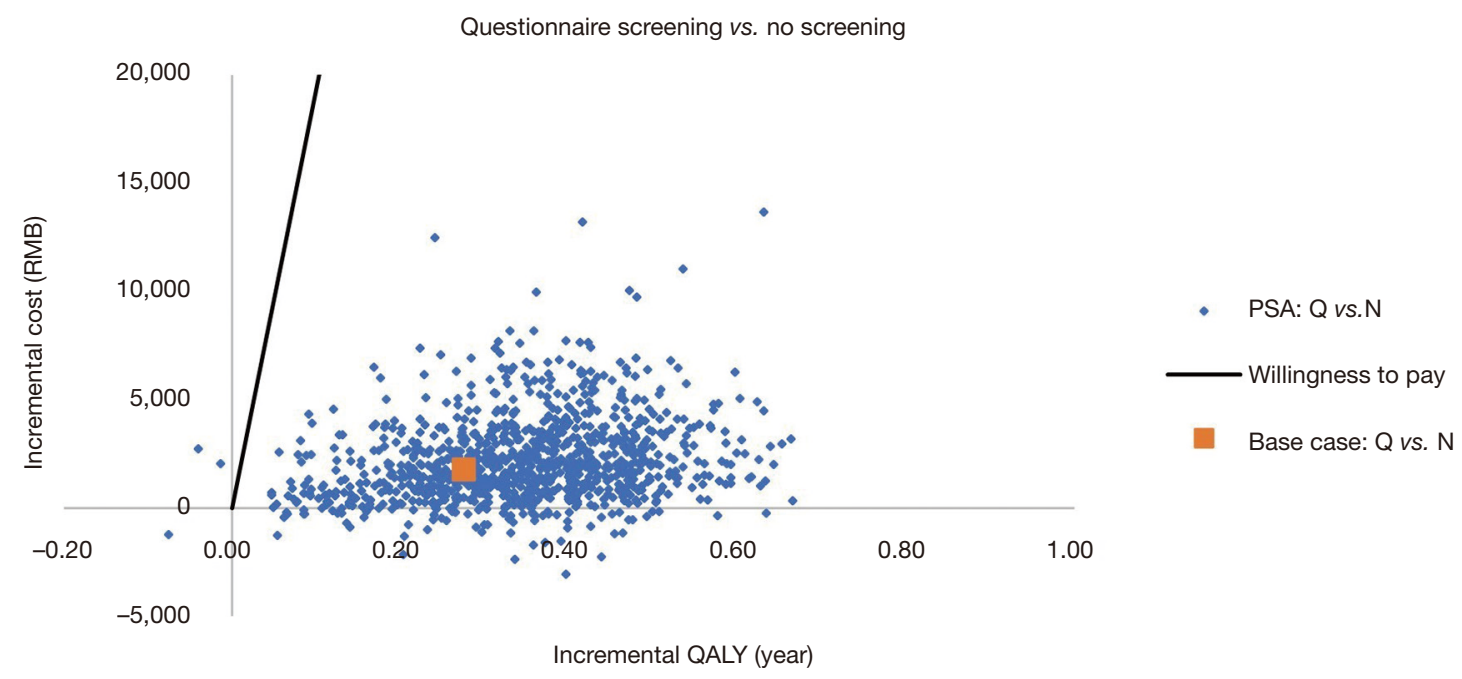

Figure 2 Probabilistic sensitivity analysis result. PSA, probabilistic sensitivity analysis; Q, questionnaire screening; N, no screening.

and important links in achieving the goal of preventing, treating, and controlling COPD. How to effectively screen out potential COPD patients is an important challenge to primary medical institutions. Currently, domestic and foreign guidelines all recommend pulmonary function testing as the gold standard for the diagnosis of COPD, but this test is often not available in primary medical institutions and rural areas, which has caused many COPD patients in these counties delaying diagnoses and thus miss the best time for treatment. It would be possible that
$85 \%$ of COPD patients should have been early detected up to 5 years before end up being diagnosed (18). The pulmonary function test generally needs to be performed in the pulmonary function room, in which the instrument is installed in a fixed position and needs calibration before use, and the test takes a long time. The instrument also needs regular maintenance, which is costly. All of these have limited the popularization of pulmonary function tests and have made it inconvenient to those with mobility difficulties, so this test is not suitable for the screening on people from 
rural counties. The simple pulmonary function instrument, being easy to operate, portable, and affordable, is suitable and feasible to use in primary medical institutions. There are no significant differences between the data acquired through a multifunctional lung tester in the pulmonary function room and the main indicators acquired through the simple pulmonary function instrument (19-23), so the latter can be used in primary medical institutions to conduct examinations for the early detection of potential COPD. In this study, we first screened the high-risk factors of COPD, and then performed a simple on-site pulmonary function test on people with high risk, which improved the detection rate of COPD, decreased the detection cost, and facilitated the early detection, early diagnosis, and early treatment of COPD patients in primary county-level medical institutions.

We identified COPD high risk patients from their total COPD-PS score ( $\geq 5) .202(53.30 \%)$ patients out of 379 respondents who presented a valid questionnaire were categorized as the COPD high risk group, of whom 92 $(24.27 \%)$ were diagnosed with COPD with the portable pulmonary function tester. This diagnosis rate of COPD was higher than that previously obtained in rural areas of China (9.6\%), likely because the screened population in this study was a COPD high risk population. The high COPD detection rate in the high risk population through the screening questionnaire also suggests that through the screening and management of high risk factors, the detection rate of COPD in the population can be improved to a certain extent, and the incidence of COPD can be further reduced through early intervention.

We found that among the 379 screened individuals, those aged over 60 predominated, and men outnumbered women. Some patients already had common complications of COPD (hypertension, emphysema, heart disease, pneumonia, tuberculosis, cerebral infarction) and a common history of exposure to COPD risk factors (smoking) and had a high COPD-PS score $(6.59 \pm 1.81)$, indicating that the prevalence characteristics of COPD patients in rural areas are identical to those in cities in terms of sex and age (24), but the COPD patients in rural areas generally have inadequate COPD health education, awareness, and attention. Among the 92 diagnosed patients in this study, 41 were already in the moderate or severe stage at the time of diagnosis, with a poor prognosis and seriously impaired quality of life. Therefore, it is necessary to improve the awareness of this disease in rural areas.

In previous COPD screening, cost-effectiveness evaluations of the data were lacking. For this reason, we adopted a published economic model to evaluate the cost-effectiveness of the early screening and found that for patients with COPD high risk, the patients who had received early screening had greater QALYs than those who had not been screened. Therefore, the willingnessto-pay threshold derived from the increased QALYs was much higher than the increased treatment cost, which could significantly cut the high medical expenses that may be caused by acute exacerbation of COPD in the later stage and thus ease the pressure on local medical insurance bureaus. The screening conducted in this study helped improving the future quality of life of many patients and was highly praised by the patients and their families, which has laid a solid foundation for the continued development of screening activities.

This screening program reported in this study still has certain limitations. The included population was those with underlying lung diseases. The questionnaire survey (COPD-PS score $\geq 5$ ) and the pulmonary function test $\left(\mathrm{FEV}_{1} / \mathrm{FVC}<0.7\right)$ indicate obstructive ventilatory dysfunction, which was used as the diagnostic basis for COPD. The results of chest radiographs were not integrated into the confirmation, so the patients with a positive final screening result may be mistakenly included in the population with other lung diseases that also involve obstructive ventilation dysfunction (e.g., bronchiectasis, bronchial asthma, bullae, lung cancer, etc.). As one of the sponsors of the screening program, the Fengning Manchu Autonomous County Hospital has provided a green passage for follow-up screening to the population with a positive screening result so that COPD patients can be confirmed and further treatment, management, and follow up.

Moreover, we confirmed the cost-effectiveness benefit of early screening. Therefore, in the future, we should improve the awareness of COPD, attach more importance to COPD screening, and strengthen medical staff's knowledge about COPD and pulmonary function as well as the clinical practice training at primary medical institutions during the two-way referral process. By employing various measures such as Internet web pages, WeChat, etc., we should perform patient education in local communities to improve their COPD knowledge and their prevention and treatment awareness and to formulate policies to encourage the use of existing screening tools or methods in the screenings. We should develop industry standards to standardize screening method or strategy. In the meantime, we should actively study COPD in Chinese rural areas to provide evidentiary 
support for the promotion of COPD screening methods or strategies.

\section{Acknowledgments}

Funding: None.

\section{Footnote}

Reporting Checklist: The authors have completed the MDAR reporting checklist. Available at http://dx.doi.org/10.21037/ apm-21-812

Data Sharing Statement: Available at http://dx.doi. org/10.21037/apm-21-812

Conflicts of Interest: All authors have completed the ICMJE uniform disclosure form (available at http://dx.doi. org/10.21037/apm-21-812). The authors have no conflicts of interest to declare.

Ethical Statement: The authors are accountable for all aspects of the work in ensuring that questions related to the accuracy or integrity of any part of the work are appropriately investigated and resolved. This study was approved by the ethics committee of Fengning Manchu Autonomous County Hospital (approval number: 2021-01), and all subjects signed the informed consent agreement. All procedures performed in this study involving human participants were in accordance with the Declaration of Helsinki (as revised in 2013).

Open Access Statement: This is an Open Access article distributed in accordance with the Creative Commons Attribution-NonCommercial-NoDerivs 4.0 International License (CC BY-NC-ND 4.0), which permits the noncommercial replication and distribution of the article with the strict proviso that no changes or edits are made and the original work is properly cited (including links to both the formal publication through the relevant DOI and the license). See: https://creativecommons.org/licenses/by-nc-nd/4.0/.

\section{References}

1. Denholm R, Schüz J, Straif K, et al. Is previous respiratory disease a risk factor for lung cancer?. Am J Respir Crit Care Med 2014;190:549-59.

2. Gonzalez J, Marin M, Sanchez-Salcedo P, et al. Lung cancer screening in patients with chronic obstructive pulmonary disease. Ann Transl Med 2016;4:160.

3. Zhou W, Du X. Morbidity Rate of COPD among High Risk Populations in the Community. Chinese General Practice 2011;14:2197-200.

4. Zhong N, Wang C, Yao W, et al. Prevalence of chronic obstructive pulmonary disease in China: a large, population-based survey. Am J Respir Crit Care Med 2007;176:753-60.

5. Wang C, Xu J, Yang L, et al. Prevalence and risk factors of chronic obstructive pulmonary disease in China (the China Pulmonary Health [CPH] study): a national cross-sectional study. Lancet 2018;391:1706-17.

6. Kjeldgaard P, Lykkegaard J, Spillemose H, et al. Multicenter study of the COPD-6 screening device: feasible for early detection of chronic obstructive pulmonary disease in primary care? Int J Chron Obstruct Pulmon Dis 2017;12:2323.

7. Thorn J, Tilling B, Lisspers K, et al. Improved prediction of COPD in at-risk patients using lung function prescreening in primary care: a real-life study and costeffectiveness analysis. Prim Care Respir J 2012;21:159-66.

8. Singh D, Agusti A, Anzueto A, et al. Global strategy for the diagnosis, management, and prevention of chronic obstructive lung disease: the GOLD science committee report 2019. Eur Respir J 2019;53:1900164.

9. Martinez FJ, Raczek AE, Seifer FD, et al. Development and initial validation of a self-scored COPD Population Screener Questionnaire (COPD-PS). COPD 2008;5:85-95.

10. Mohamed Hoesein FA, Zanen P, Sachs AP, et al. Spirometric thresholds for diagnosing COPD: 0.70 or LLN, pre- or post-dilator values? COPD 2012;9:338-43.

11. Qu S, You X, Liu T, et al. Cost-effectiveness analysis of COPD screening program in primary care for high risk patients. ISPOR 2019, New Orleans, US.

12. In 2019, China's GDP reached nearly 100 trillion yuan, an increase of $6.1 \%$ 2020. Available online: http://www.gov. cn/xinwen/2020-01/18/content_5470531.htm

13. GBD 2015 Chronic Respiratory Disease Collaborators. Global, regional, and national deaths, prevalence, disability-adjusted life years, and years lived with disability for chronic obstructive pulmonary disease and asthma, 1990-2015: a systematic analysis for the Global Burden of Disease Study 2015. Lancet Respir Med 2017;5:691-706.

14. Wang H, Wei S, Liang S, et al. The Studies on Early Diagnosis and Intervention of Asymptomatic Chronic Obstructive Pulmonary Disease. Medical Recapitulate 2014;20:946-8. 
15. Pan Z, Chi C, Zheng J. Review of Screening Methods for Chronic Obstructive Pulmonary Disease in Primary Care. Chinese General Practice 2020;23:257-66.

16. Zhou Y, Zhong N, Li X, et al. Tiotropium in early-stage chronic obstructive pulmonary disease. $\mathrm{N}$ Engl J Med 2017;377:923-35.

17. Peng X, Huang M, Zhao W, et al. Delayed diagnosis is associated with greater disease severity of chronic obstructive pulmonary disease. Journal of Southern Medical University 2018;38:1448-52.

18. Jones RC, Price D, Ryan D, et al. Opportunities to diagnose chronic obstructive pulmonary disease in routine care in the UK: a retrospective study of a clinical cohort. Lancet Respir Med 2014;2:267-76.

19. Jiang H, Tong X, Chen J, et al. Screening Methods and Characteristics of Chronic Obstructive Pulmonary Disease in Rural Grassroots. Chinese Primary Health Care 2020;34:21-4.

20. Yu M, Gao Y, Wang S, et al. Effect of simple pulmonary

Cite this article as: $\mathrm{Du} \mathrm{M}, \mathrm{Hu} \mathrm{H}$, Zhang L, Liu W, Chu T, Wu G, Wang X, Li L, Wang J, Zheng L, Bai S. China county based COPD screening and cost-effectiveness analysis. Ann Palliat Med 2021;10(4):4652-4660. doi: 10.21037/apm-21-812 function meter in community screening of chronic obstructive pulmonary disease. Chronic Pathematology Journal 2018;7:851-2.

21. Wang W, Ma X, Wei X, et al. Screening procedures and techniques for chronic obstructive pulmonary disease in the community. Chinese Journal of Gerontology 2017;37:138-40.

22. Pan S, Hong Q, Zhao R. Application of COPD-6 handheld spirometer in monitoring chronic obstructive pulmonary disease. J Mathematic Med 2016;29:444-5.

23. Li X, Zhang Y, Zhou J, et al. Feasibility analysis of screening COPD with portable pulmonary function test equipment in community. J Clin Pulmonary Med 2020;25:834-8.

24. Zhang S, Sun L, Zhang J. Epidemiological Investigation of Community COPD and Strategy of Health Education. Nursing Journal of Chinese People's Liberation Army 2007;24:20-2. 